\title{
Review: effect of environmental cadmium pollution on human health
}

\author{
Jing-Xiu Han ${ }^{1}$, Qi Shang ${ }^{1}$, Yu Du² \\ ${ }^{1}$ Department of Epidemiology and Health effects, Institute for Environmental Health and Related Product Safety, Chinese Center for \\ Disease Control and Prevention, 29 Nanwei Road, Beijing, 100050, China; Corresponding author: sqyoux@yahoo.com.cn (Qi Shang) \\ ${ }^{2}$ Yuzhong district centre for disease control and prevention, Chongqing Municipality
}

Received 14 August 2009; revised 1 September 2009; accepted 2 September 2009.

\begin{abstract}
Based on the available data obtained from the population investigating, the authors reviewed research articles of the study on analytical methods and exposure levels of cadmium (Cd) in population, the injury of target organ, the evolvement of sensitive index for surveillance, the study on effects of human disease and death for environmental $\mathrm{Cd}$ exposure, and the study on priority surveillance of human health risk.
\end{abstract}

Keywords: Cadmium Pollution; Population Investigation; Disease Surveillance; Renal Damage

\section{INTRODUCTION}

Cadmium (Cd) is a toxic heavy metal which can be accumulated in human body and environment long-term. The health risks of environmental $\mathrm{Cd}$ pollution have caused the concern all over the world since the "itai-itai" disease caused by chronic $\mathrm{Cd}$ poisoning appearing in Japan in 1950's. Series of criteria and guidelines have been developed in many countries and international organizations to guide the study on health effect of Cd pollution. $\mathrm{Cd}$ has been ranked at the sixth of toxic substances for significant human health hazard by U.S Poison and Disease Registry [1]. At the same time, this element has been a focus of study on environmental pollution in the United Nations Environment Programs and the International Commission on Occupational Health. It was also put on a priority position of the study on food contamination in the World Health Organization [2]. Cd pollution of industrialization began in the early 1960's in China and then many studies on popular health effects of environmental Cd pollution have been carried out in 1980's and early of 1990's. It was estimated that the total area polluted by $\mathrm{Cd}$ in China is more than 11000 hectares, and there were 11 provinces and municipalities, 25 territories production Cd-polluted rice (Cd concentration 1.32 5.43 $\mathrm{mg} / \mathrm{kg}$ ) (Ministry of Farming Animal Husbandry and Fisheries, Beijing, Internal report, 1980). Annual amount of Cd with industrial waste discharged into the environment was more than 680 tons $[3,4]$. Unfortunately, there were few researches of Cd pollution on human health effects after the 1990s in China besides some follow up investigations of resident's health effects which were carried out only in a few contaminated areas. It is these studies that showed the Cd-polluted actives have not been efficiently dealt with over last 20 years in China, and the health risk of residents living in contaminated areas has been becoming more serious than those in the 1980's [5-8]. The environmental Cd exposure occurs mainly in Japan and China. In other countries, the intensity and duration of Cd exposure and the injury occurring in populations are in a relatively low level, with little related literature reported $[9,10]$.

Population expositing to environmental pollutants has a general character of low-dose, long-term, and chronic poisoning, which will cause two different kinds of chronic health effects, damage of target organs and nonspecific changes for population such as weakness, ease to suffering from illness and rise of morbidity and mortality etc. In this paper, the information from population-based study on human health effects of environmental Cd pollution was reviewed.

\section{TARGET ORGANS DAMAGE OF ENVIRONMENTAL Cd EXPOSURE}

Main work of study on popular health effects caused by environmental $\mathrm{Cd}$ pollution can be divided into different scopes: target organ (kidney, bone, prostate, etc.) damage, biomonitoring, dose-response relationship, investigation of exposure level, mortality, and survival analysis [11]. There were some studies on mortality and survival analysis in recent years in China [8].

\subsection{Target Organ Damage and Biomonitoring}

Based on results of toxicological studies, the researches 
on human specific-injury caused by $\mathrm{Cd}$ exposure have focused on injury biomonitoring of bones and urogenital system. The main researches were early screening for the early sensitive biomonitoring indices, monitoring and evaluation of target organ damage, and study on the doseresponse relationship between $\mathrm{Cd}$ exposure and health damage indices. There were a lot of early indices of kidney damage applied in the popular surveys. Some were related to body burden of $\mathrm{Cd}$ exposure, such as blood $\mathrm{Cd}$ (B-Cd) and urinary $\mathrm{Cd}(\mathrm{U}-\mathrm{Cd})$; some were sign of bone injury, such as bone mineral density (BMD), urine calcium, urine phosphorus, urine or serum alkaline phosphatase (U-, BALP), urine hydroxyproline (U-HOP), and so on. Index commonly used to show $\mathrm{Cd}$ accumulation level in renal cortex and the whole body was U-Cd. There are generally two different kinds of groups of biomonitoring indices for renal tubular dysfunction and renal tubular pathological damage: urine protein and urine enzyme. The former included urine $\beta_{2}$-micro-globulin $\left(\mathrm{U} \beta_{2}-\mathrm{MG}\right), \alpha_{1}$-microglobulin $\left(\mathrm{U} \alpha_{1}-\right.$ $\mathrm{MG})$, retinolbinding protein (U-RBP), metallothionein (UMT), albumin (U-ALB), amino acids, and so on. The latter were urine $\mathrm{N}$-acetyl- $\beta$-D-glucosaminidase (U-NAG), alkaline urine (U-ALP), and $\gamma$-glutamyltranspeptidase enzyme $(\gamma-\mathrm{GT})$, etc $[5,9,12]$. Urine enzyme was mainly from renal tubular epithelial cell, therefore, changes of enzyme activity in urine had been considered as representative indicator of renal tubular injury comparing with urinary protein serving as tubular re-absorption dysfunction indicator. However, the most commonly used indices were $\mathrm{U}-\mathrm{Cd}, \mathrm{U} \beta_{2}-\mathrm{MG}$, and U-NAG (U-NAG applying in 3 ways: A-isozyme, B-isozyme and total NAG, renal tubular epithelial cells are rich in B-NAG), among which good correlations have been observed. Early sensitivity of urinary enzymes or urine protein reported in many literatures. It is a result of the survey reported by different authors carrying out at different $\mathrm{Cd}$ exposure stages, different accumulating $\mathrm{Cd}$ exposure level causing different health effects. Analyzing the progress of chronic $\mathrm{Cd}$ poisoning, the urinary protein mainly from the serum did not increase significantly when there was no renal glomerulus and re-absorptive in the early stage. In this period, phenomena of $\mathrm{Cd}$ nephrotoxic was a rise in U-Cd and urinary enzymes. With the increase in $\mathrm{Cd}$ exposure level, U-Cd, urine enzyme and urine protein would be synchro-increasing, it was a sign of renal tissue injury with renal dysfunction. The renal tubular injury induced by environmental $\mathrm{Cd}$ exposure was irreversible even after soil replacement in $\mathrm{Cd}$-polluted rice paddies [13-15]. In the late stage of Cd exposure, it would be seen that U-Cd and urinary protein increased sharply with urinary enzyme active reducing. Therefore, in practice, application of specific biomonitoring indicators and result analysis should consider the levels of U-Cd and cumulative $\mathrm{Cd}$ exposure of population in different contaminated areas $[16,17]$. It was estimated based on literatures that some of above indicators appearing in the urine in correspondence to 24-hour urinary $\mathrm{Cd}$ concentrations were: Ca: $1.9 \mu \mathrm{g}, \mathrm{U}-\mathrm{NAG}: 2.74 \mu \mathrm{g}, \mathrm{U}-\mathrm{RBP}: 2.87 \mu \mathrm{g}, \mathrm{U} \beta_{2}-\mathrm{MG}$ : $3.05 \mu \mathrm{g}$, amino acids: $4.29 \mu \mathrm{g}$. In addition, when U-Cd began to rise abnormally, the other biomarks would be at the levels of: U-NAG: $2.74 \mu \mathrm{g}, \mathrm{U}-\mathrm{RBP}: 338 \mu \mathrm{g}, \mathrm{U} \beta_{2}-\mathrm{MG}$ : $283 \mu \mathrm{g}$ [10]. If an individual has synchronized with increasing in the levels of $\mathrm{U}-\mathrm{Cd}, \mathrm{U} \beta_{2}-\mathrm{MG}$ and $\mathrm{U}-\mathrm{NAG}$ over national standard value, it would mean that the individual's health had been severely damaged suffering from environmental $\mathrm{Cd}$ pollution. And if there were $10 \%$ individuals with severe health damage in a contaminated area at the same time, it would be judged to be a contaminated area with popular health damage according to the health standards of China [18]. Government should take action to control environmental pollution and prevent residents in the area from $\mathrm{Cd}$ health damage.

The first change of biomark index corresponding to environmental $\mathrm{Cd}$ exposure was the increase of $\mathrm{U}-\mathrm{Cd}$. When the level of U-Cd arrived at approximately $2.5 \sim 5.0 \mu \mathrm{g} / \mathrm{g}$, the indices of renal dysfunction and renal tubular injury began to change [19-22]. However, some researchers [8,23, 24] calculated benchmark doses (BMDs) of U-Cd and their 95\% lower confidence bounds (BMDLs) for renal effects of $\mathrm{Cd}$ in a population with low environmental exposure. Yasushi et al. [23] obtained BMDs of U-Cd were lower than the critical concentrations previously reported. For both NAG and protein HC, the BMDs (BMDLs) of U-Cd were $0.5-1.1(0.4-0.8) \mu \mathrm{g} / \mathrm{L}$ (adjusted for specific gravity of $1.015 \mathrm{~g} / \mathrm{ml})$ and $0.6-1.1(0.5-0.8) \mu \mathrm{g} / \mathrm{g}$ creatinine. But considering age effect, it was important to establish the threshold level of $\mathrm{Cd}$ exposure at each age $[14,15]$. In the late of chronic $\mathrm{Cd}$ poisoning, with $\mathrm{U}-\mathrm{Cd}$ and $\mathrm{U} \beta_{2}-\mathrm{MG}$ significantly increasing [25-27], the bone injury indicators and U-ALB were expected to show a significant change. Usually, bone damage was a delayed sign of severe chronic Cd poisoning. Population-based studies [28-31] showed an association between osteoporosis and low-level environmenttal $\mathrm{Cd}$ exposure. $\mathrm{Cd}$ can cause bone demineralization, either through direct bone damage or indirectly as a result of renal dysfunction. Result of a study [32] indicated that excretion of urinary Vitamin D-binding protein (DBP, which binds, transports and activates vitamin $\mathrm{D}$, plays a major role in calcium homeostasis and bone turnover) in urine may be linked to renal tubular dysfunction and possibly bone lesions in the inhabitants of Cd-polluted areas. Nordburg et al. $[33,34]$ reported that the BMD decrease in postpartum women with raised levels of $\mathrm{U}-\mathrm{Cd}$ or $\mathrm{B}-\mathrm{Cd}$, and BMD decrease in men with increased levels of B-Cd in Asia excluding Japan. Kido's [35] studies had shown that the urinary indicators of renal function $\left(\beta_{2}-\mathrm{MG}\right)$ and indicator of $\mathrm{Cd}$ exposure in male and female were negatively correlated with the central part of the second metacarpal BMD. Cd induced the disorders of normal osteoblasts and bone metabolism through disrupting calcium messenger system, led to osteomalacia, increased the dissolution of 
calcium, decreased BMD, and caused osteoporosis [36]. Environmental Cd exposure may also be associated with increased risk of dental caries in deciduous teeth of children [37].

Jin et al. $[38,39]$ had reported prostate damage induced by $\mathrm{Cd}$, but little information was provided in population research.

\subsection{Estimation of $\mathrm{Cd}$ Intake Level}

Early research on the population $\mathrm{Cd}$ intake levels mainly focused on estimating daily intake. It was a static mode and just got a cross-sectional data at surveying day. This method could not get accumulation exposure level, a very important data to observe and research a relationship between $\mathrm{Cd}$ intake and chronic health damage. For this reason, many people used total intake (or the cumulative intake) to find out the relationship between accumulative $\mathrm{Cd}$ intake and health chronic injury as well as key point of chronic damage at different total intake level, which would be corresponding to different degree of health injury $[40,41]$. Japanese scholars reported their result that they used the data of daily intake level multiplying by total exposure days to estimate population total intake level [42-44]. This method did not consider a difference in food intake levels at different age stages, generally, and the amount estimated in this method might be greater than actual intake level. There were some scholars who calculated the Cd total intake through way of estimating the cumulative rice consumption. Two different methods were accepted to estimate the cumulative rice consumption. One method is that total rice consumption was calculated using consumption in various age groups, which was estimated based on the curve equation of daily average rice consumption in various age groups [40], the another way, which used coefficient to estimate, the total rice con- sumption was reckoned according to various coefficients of various age groups. The coefficients were set as follows, $0 \sim 9$ age group: $0.413,10 \sim 19$ age group: $0.885,20 \sim 59$ age group: 1, and age group beyond 60: 0.823 [41]. Two kinds of methods both considered the differences in dietary consumption in children and elder population, and the calculated results were also similar (estimated $\mathrm{Cd}$ intakes for the 45-year-old group are $161 \mathrm{mg}$ and $166 \mathrm{mg}$, respectively). Chiyoda [45] used urine protein and urine sugar as biomonitoring indicators, and estimated that the allowed total intake of $\mathrm{Cd}$ in Japanese was less than $1.58 \mathrm{~g}$ in their life. Due to the lack of continuous monitoring data, the estimating value of population total intake was a relative result, it would be mainly applied in evaluating the group exposure, and considered only as a reference value when used to identify the health damage of individual [40].

\subsection{Dose-Response Relationship on Cd Exposure}

It has been possible to link the total $\mathrm{Cd}$ intake with population health damage dynamically by calculating accumulative $\mathrm{Cd}$ intake so that a regress formula could be gotten between population health damage degree and $\mathrm{Cd}$ exposure dose. The result of digitizing health damage degree makes it possible to compare all of information from different authors' studies in a dosage scale. Health damage degree corresponding to different accumulative exposure dose could also be used to predict the tendency of population health damage caused by $\mathrm{Cd}$ exposure which based on the data of environmental monitoring or biomonitoring. A large number of articles had reported the dose-response relationship between the total $\mathrm{Cd}$ exposure and biomonitoring indicator of popular health injury, and explored the level of $\mathrm{Cd}$ exposure associated with the degree of health injury. These reports about dose-response relationship focused on the association between $\mathrm{Cd}$ exposure and indicators of renal injury, such as: U-Cd and U $\beta_{2}-\mathrm{MG}, \mathrm{U}-\mathrm{NAG}, \mathrm{U}-\mathrm{RBP}$, and so on. The estimation of total exposure level laid basis on the unit of population group, which corresponded to the incidence of abnormal value of a variety of monitoring indicators, the occurrence of specific chronic diseases, such as fracture morbidity and mortality of "itai-itai" disease. Some authors had used $\mathrm{U}-\mathrm{Cd}$ as indicator of $\mathrm{Cd}$ exposure to that of responsive renal injury indicator to calculate relationship between exposure and response, and observe development trend and degree of renal injury [46-48]. Japanese scholars also used $\mathrm{Cd}$ concentration of rice in different regions, corresponding to incidence of abnormal monitoring indicators, to calculate dose-response relationship. Nevertheless, this method which only provided a relationship between different exposure level and indexes of popular health damage just was a static model of dose-response relationship.

\subsection{Mortality and Survival Analysis of Population Exposed to Environmental Cd}

Mortality of people exposed to environmental $\mathrm{Cd}$ had been reported in China and Japan. Kawana [49] reported the mortality rate of "itai-itai" disease was $72.6 \%$ (50.4\% in control group) from 1967 to 1982 , the average survival time was 76.4 year-old (control group: 78.3 year-old) with statistically significant differences. Kobayashi [50] had studied on relationship between the level of urine calcium and life expectancy, as well as the number of female pregnancy and childbirth associating with popular mortality. He found that the lower urine calcium, the shorter life-span. But popular mortality was not associated with the number of pregnancy and childbirth. Death analysis in Japan mainly adopted a method of following-up observation [51,52]. Based on the biomonitor data from past population-based survey, they collected the data of death records from Cd contaminated areas and analyzed mortality and survival time to observe the changes of popular renal injury indicators, such as $\mathrm{U}-\mathrm{Cd}, \mathrm{U} \beta_{2}-\mathrm{MG}, \mathrm{U}-\mathrm{RBP}$ and so on, in the areas where populations had exposed to 
environmental $\mathrm{Cd}$ at different levels. Different from common disease surveillance, there was no cause-specific death or disease-specific mortality reported in those reports. Since the discovery of itai-itai disease, Japanese scholars had observed and studied on the damage of the death in Cd-exposure population. The studies had shown that higher volume of $\mathrm{Cd}$ in rice caused population higher $\mathrm{Cd}$ exposure, and then could induce population to have a series of health effects, such as more severe renal injury, higher mortality, shorter survival time, and more unfavorable the prognosis [48,50,53-56]. Even if zinc-Cd smelters closed, historical environmental contamination remained a persistent source of exposure. Environmental exposure to $\mathrm{Cd}$ increased total, and noncardiovascular mortality in a continuous fashion without threshold $[57,58]$. One study [59] found that environmental $\mathrm{Cd}$ exposure was associateed with an increasing risk of all cause, cancer, and cardiovascular disease mortality among men, but not among women. Additional efforts are warranted to fully explain gender differences on the impact of environmental $\mathrm{Cd}$ exposure.

\section{HUMAN NON-SPECIFIC DAMAGE FROM ENVIRONMENTAL Cd POLLUTION}

In addition to target organ damage, there were still some non-specific impacts of environmental $\mathrm{Cd}$ pollution on the human health. Low IgG level of children with higher $\mathrm{Cd}$ body burden suggested that $\mathrm{Cd}$ could affect development of children's immune system. According to the detection of immunoglobulin sub-type, $\mathrm{IgG}_{3}$ was the most sensitive to the inhibitory effect of $\mathrm{Cd}$, followed by: $\mathrm{IgG}_{1}$, $\mathrm{IgG}_{2}, \mathrm{IgM}$ and $\mathrm{IgG}_{2 \mathrm{a}}$. Therefore, IgG could be used as the sensitive indicator of immune suppression of children exposed to Cd [60]. EU Toxicology, Eco-toxicology and Environmental Science Committee had agreed with the opine that $\mathrm{Cd}$ exposure could have immunosuppressive effects [61]. Gary [21] reported that the urine $\mathrm{Cd}$ in 3 levels of $0 \sim 0.99 \mu \mathrm{g} / \mathrm{g} \mathrm{Cr}$ (control group), $1.00 \sim 1.99 \mu \mathrm{g} / \mathrm{g} \mathrm{Cr}$ and $\geq 2 \mu \mathrm{g} / \mathrm{g}$ Cr respectively, its OR for the early stage of diabetes were: 1.48 (95\%CI: $1.21 \sim 1.82)$ and 2.05 (95\%CI: 1.42 2.95); the OR for type II diabetes: 1.24 (95\%CI: 1.06 1.45) and 1.45 (95\%CI: 1.07 1.97) [2]. Early diabetes (IFG) and type II diabetes had significant doseresponse relationships with urinary $\mathrm{Cd}$ concentration, it suggested that the two kinds of human diseases had related to the $\mathrm{Cd}$ exposure.

Many literatures reported the impact of $\mathrm{Cd}$ on human reproductive system. Falcon [62] reported that pregnant women exposed to environmental $\mathrm{Cd}$ might have an adverse effect in perinatal period, e.g. fetal growth retardation, low birth weight, birth deformities and premature. Nishijo et al [63-65] reported that mothers with higher urinary $\mathrm{Cd}$ concentration would be company with higher levels of $\mathrm{Cd}$ and lower calcium concentration in their breast milk. $\mathrm{Cd}$ exposure may be a possible cause of male infertility. A significant negative correlation was observed between serum Cd level and all examined biophysical semen characteristics except sperm volume [66].

Nishijo et al. [55,67] reported that there were doseresponse relationships between $\mathrm{Cd}$ exposure and mortality risks in both male and female in the $\mathrm{Cd}$ contaminated areas. Chronic exposure to $\mathrm{Cd}$ could increase popular mortality and shorten life expectancy. In recent years, a 15-year-follow-up investigation of 3119 residents living in $\mathrm{Cd}$ polluted area had confirmed that $\mathrm{Cd}$ exposure was associated with popular mortality [55]. Another survey found the standardized mortality rates of six kinds of diseases in Cd contaminated areas were higher than noncontaminated areas, such as cancer, respiratory disease and cerebrovascular disease. Some population-based studies reported that $\mathrm{Cd}$ exposure was associated with increased risk of breast and endometrial cancer [68-70]. These might because that $\mathrm{Cd}$ mimicked the function of steroid hormones [71]. Moreover, data suggested that $\mathrm{Cd}$ exposure was associated with increasing testosterone levels [72]. High testosterone levels have been associated with the risk of breast cancer. But more experimental and epidemiological studies are required to establish a cause and effect association between the metal and hormone dependent cancers and to verify the mechanism of action. $\mathrm{Cd}$ exposure via inhalation might associate with some human cancers, but Verougstraete [73] did not think that it could cause human cancer exposing to environ- mental $\mathrm{Cd}$. Cd levels in blood were associated with a modest elevation in blood pressure [74]. A 15-year-follow-up study found that mortality for heart failure and cerebral infarction was increased among inhabitants living in a Cd-polluted area in Japan [54].The incidence of subhealth state of population in $\mathrm{Cd}$ pollution area was higher than that of people in non-polluted area, such as dizziness headache, loss of appetite, coughing, shortness of breath, etc. The morbidity of chronic disease was also significantly higher than that of people in non-polluted area, such as stomach and duodenal ulcer, bronchitis, urinary calculi, and so on. The health status of residents in the polluted area had been impacted by the environmental $\mathrm{Cd}$ pollution, the infant mortality. The pre-mature deliver rate in the $\mathrm{Cd}$ polluted area was higher than those of control area, and the spectrum of popular disease and death in polluted area was significantly high than those of people in control area $[75,76]$.

Some research data [77] indicated that $\mathrm{Cd}$ exposure could result in pancreatic dysfunction and the effect appeared at lower urinary $\mathrm{Cd}$ level than renal dysfunction. But more studies were needed to prove it.

The research data on non-specific hazards of environmental Cd pollution was not too much, because the health effects of population were characterized by target organ damage in the early stage of chromic Cd poisoning, which had led main studies focusing on effects of renal injury, a 
special-effects, in a long time, yet few investigations on the change of popular mortality and morbidity of environmental Cd exposure.

\section{MONITORING AND EARLY WARNING STUDIES ON POPULATION HEALTH HAZARDS}

Thacker [78] put forward the concept of Environmental Public Health Surveillance (EPHS) in 1996. The U.S. Center for Disease Control and Prevention (CDC) has been laying the groundwork for what was planned to become a nationwide environmental public health track network in 2002 for integrating network to assess local and state data to determine exposures and health effects linked to environmental hazards. CDC also provided the EPHS system with a set of environmental public health indicator (EPHI) in 2003, including: 1) hazard indicators (Conditions or activities that identify the potential for exposure to a contaminate or hazardous condition); 2) exposure indicators (Biological markers in tissue or fluid that identify the presence of a substance or combination of substance that could harm an individual); 3 ) health effect indicators (Disease or condition that identify an adverse effects from exposure to a known or suspected environmental hazard); 4) intervention indicators (programs or official policies that minimize or prevent an environmental hazard, exposure, or health effect). Projectspecific monitoring indicators needed to meet the following requirements: 1) measurable; 2) trackable over time; 3) based on demonstrated links between environment and health; 4) useful and understood by diverse populations; 5) informative to the public and to responsible agencies; 6) tied to public health objectives; 7) action-oriented; 8) incorporated in clear-case definitions [79]. In 2005, the U.S CDC announced the launch of national network-building projects EPHS. Combining with population disease information, EPHS would help to assess hazard factors in the environment, the main exposure routes, the health effects of population and time trends through monitoring environmental harmful factors, investigating the exposure routes and identifying people at risk, timely releasing and delivering relevant information to help high-risk people to avoid the exposure to hazard factors and reducing the incidence of chronic diseases in population. Its basic object was to realize the integration of disease and death data monitored continuously and routinely with the occasional professional investigation of environmental risk factors and the individual-based population health evaluation data. EPHS was different from any other existing monitoring system. Its characteristics included: identify the health effect trend of population exposed to environmental risk factors based on the routine analysis of data on population disease and death; determine the environmental risks and population health status through professional targeted research [80]. The raise of EPHS concept was the overthrow of conventional route of monitoring and early warning study on population health risks. It was combined with environmental benchmark dose exposure and referred to the EAI (environmental accident index) indicators. The integration of environmental hazard surveys monitoring data and human disease surveillance data provided scientific opportunities for the development of population health hazard monitoring and early warning system studies. EPHS was expected to be an ideal technical platform, which was able to integrate all kinds of disease control tasks and disciplines in the field of environmental health and combine the main tasks of CDC at all levels.

\section{RESEARCH OBJECTIVES IN THE FUTURE}

It is very important to explore the risk factor for "Itai-Itai" disease exposed to environmental $\mathrm{Cd}$ continuously in long time and at high level, which has already existed in China [81]. It is not time to say stop, although great achievement has been made in study on health effect of exposure to environmental $\mathrm{Cd}$. There is a lot of work needed to do for realizing $\mathrm{Cd}$ health risk well in the future. The main research objects should focus on: 1) continue to conduct follow-up study on health hazards of all kinds of people, evaluate the population $\mathrm{Cd}$ exposure and the severity of health damage related, and analyze its trend; 2) concern about the human disease and death impact due to $\mathrm{Cd}$ exposure, collect and screen the information of population disease and death closely related to $\mathrm{Cd}$ exposure, and study the link and dose-response relation-ship between kidney damage and $\mathrm{Cd}$ exposure; 3) establish human health hazard monitoring and early warning network of $\mathrm{Cd}$ exposure in the framework of environmental public health monitoring; 4) implement prevention and intervention research on population health hazards of environmental $\mathrm{Cd}$ exposure to reduce the risk of population $\mathrm{Cd}$ exposure and health injury related.

\section{REFERENCES}

[1] ATSDR (Agency for Toxic Substances and Disease Registry). (1997) Toxicological Profile for Cadmium (Update).

[2] WHO (1989), Cadmium. Evaluation of certain additives and contaminants Geneva: WHO.

[3] Q. H. Kong, (2001) Human health effects for environmental cadmium pollution. Journal of Zhejiang Academy of Medical Sciences, 12(1), 1-2.

[4] J. Z. Geng, (1993) Environment and Health. Huaxia Publishing House, First Edition, 447.

[5] G. Nordberg, T. Jin, and Q. Kong, (1997) Biological monitoring of cadmium exposure and renal effects in a population group residing in a polluted area in China. Sci. 
Total Environ., 16, 199-114.

[6] J. Q. Li, X. Y. Chen, Y. J. Tang, et al., (2001) Environmental Cadmium Pollution and the Effect on Population Health. China Public Health, 17(3), 196-198.

[7] T. Y. Jin, Q. H. Kong, T. T. Ye, et al., (2002) Environmental Epidemiology: Human Health Impacts Caused by Cadmium. Journal of Labour Medicine, 9(1), 10-16.

[8] T. Jin, X. Wu, Y. Tang, et al., (2004) Environmental epidemiological study and estimation of benchmark dose for renal dysfunction in a cadmium-polluted area in China. Biometals, 17(5), 525-30.

[9] R. Dianne and J. William, (1999) Heavy metal poisoning and its laboratory investigation. Ann Clin Biochem, 36, 267-300.

[10] EPA, (1999) Toxicological review, Cadmium and Compounds (CAS No. 7440-43-9).

[11] M. M. Zhai and Q. Shang, (2007) Reseach advance of environmental cadmium exposure on human health damage. Journal of Hygiene Research, 36(2), 255-257 (Chinese).

[12] T. Kido, E. Kobayashi, M. Hayano, et al., (1995) Significance of elevated urinary human intestinal alkaline phosphatase in Japanese people exposed to environmental cadmium. Toxicol Lett., 80(1-3), 49-54.

[13] K. Etsuko, S. Yasushi, H. Ryumon, et al., (2008) Serial changes in urinary cadmium concentrations and degree of renal tubular injury after soil replacement in cadmiumpolluted rice paddies. Toxicology Letters, 176, 124-130.

[14] E. Kobayashi, Y. Suwazono, M. Dochi, et al., (2008) Estimation of benchmark doses as threshold levels of urinary cadmium, based on excretion of beta2-microglobulin in cadmium-polluted and non-polluted regions in Japan. Toxicol Lett., 179(2), 108-12.

[15] E. Kobayashi, Y. Suwazono, R. Honda, et al., (2008) Serial changes in urinary cadmium concentrations and degree of renal tubular injury after soil replacement in cadmium- polluted rice paddies. Toxicol Lett., 176(2), 124-30.

[16] H. Nakadaira and S. Nishi, (2003) Effects of low-dose cadmium exposure on biological examinations. Sci. Total Environ., 308, 49-62.

[17] K. Nogawa, T. Kido, and Z. A. Shaikh, (1992) Doseresponse relationship for renal dysfunction in a population environmentally, Cadmium in the Human Environment. IARC, 311-318.

[18] Criteria to determine health hazard district caused by environmental cadmium pollution (1998) GB/T, 17221.

[19] L. Jarup and C. G. Elinder, (1994) Dose-response relations between urinary cadmium and tubular proteinuria in cadmium-exposure workers. Am J. Ind. Med., 26, 757.

[20] Oo, Y., E. Kobayashi, K. Nogawa, Y., et al., (2000) Renal effects of cadmium intake of a Japanese general population in two areas unpolluted by cadmium. Arch. Environ. Health, 55, 98-103.

[21] I. Masayuki , E. Takafumi, M. Jiro , et al., (2005) The threshold cadmium level that causes a substantial increase in $\beta_{2}$-microglobulin in urine of general populations. Exp. Med., 205, 247-261.

[22] M. Ikeda, T. Ezaki, J. Moriguchi, et al., (2005) The threshold cadmium level that causes a substantial increase in beta2-microglobulin in urine of general populations. Tohoku J. Exp. Med., 205(3), 247-61.

[23] S. Yasushi, S. Salomon, V. Marie, et al., (2006) Benchmark dose for cadmium-induced renal effects in humans. Environ Health Perspect, 114(7), 1072-1076.

[24] E. Kobayashi, Y. Suwazono, M. Uetani, et al., (2006) Esti- mation of benchmark dose as the threshold levels of urinary cadmium, based on excretion of total protein, beta2-microglobulin, and $\mathrm{N}$-acetyl-beta-D-glucoseminidase in cadmium nonpolluted regions in Japan. Environ. Res., 101(3), 401-6.

[25] T. Y. Jin and X. W. Wu, (2003) Application of Benchmark Dose (BMD) in an Epidemiological Study on a General Population Environmentally Exposed to Cadmium. Journal of Labour Medicine, 20(5), 335-337.

[26] X. W. Wu, T. T. Ye, T. Jin, et al., (1997) Dose-response relationship between cadmium and renal dysfunction in a general population. Journal of Shanghai Medical (University), 24(1), 41-44 (Chinese).

[27] Q. Shang and S. W. Cai, (1988) Urinary N-acetyl- $\beta-D-$ gluco-saminidase and early renal damage, Foreign Medical Science-Section Hygiene, 3, 149-153 (Chinese).

[28] J. A. Staessen, H. A. Roels, D. Emelianov, T. Kuznetsova, L. Thijs, J. Vangronsveld, et al., (1999) Environmental exposure to cadmium, forearm bone density, and risk of fractures: prospective population study. Lancet, 353, $1140-1144$.

[29] R. Honda, I. Tsuritani, Y. Noborisaka, H. Suzuki, M. Ishizaki, and Y. Yamada, (2003) Urinary cadmium excretion is correlated with calcaneal bone mass in Japanese women living in an urban area. Environ. Res, 91, 63-70.

[30] G. Zhu, H. Wang, Y. Shi, S. Weng, T. Jin, Q. Kong, et al., (2004) Environmental cadmium exposure and forearm bone density. Biometals, 17, 499-503 (Chinese).

[31] M. G. Carolyn, S. K. John, and R. M., (2008) Jaymie Urinary cadmium and osteoporsis in U.S. women $\geq 50$ years of age: NHANES 1988-1994 and 1999-2004. Environ. Health Perspect, 116(10), 1338-1343.

[32] M. Uchida, H. Teranishi, K. Aoshima, et al., (2007) Elevated urinary levels of vitamin D-binding protein in the inhabitants of a cadmium polluted area, Jinzu River basin, Japan. Tohoku J. Exp. Med., 211(3), 269-74.

[33] G. Nordberg, T. Y. Jin, A. Bernard, et al., (2002) Low bone density and renal dysfunction following environmental cadmium exposure in China. Ambio, 31(6), 4782481.

[34] A. Agneta, B. Per, L. Thomas, et al., (2006) Cadmiuminduced effects on bone in a population-based study of women. Environ. Health Perspect, 114(6), 830-834.

[35] T. Kido, K. Nogawa, R. Honda, et al., (1990) The association between renal dysfunction and osteopenia: in environmental cadmium-exposed subjects. Environ. Res., 51, 71-82.

[36] T. Alfvdn, C. G. Elinder, M. D. Carlsson, et al., (2000) Low-level cadmium and osteoporosis. J. Bone Miner Res., 15, 1579-1586.

[37] A. Manish, W. Jennifer, S. Joel, et al., (2008) Association of Environmental Cadmium Exposure with Pediatric Dental Caries. Environ. Health Perspect, 116(6), 821-825.

[38] T. Jin, G. Nordberg, X. Wu, et al., (1999) Urinary $\mathrm{N}$-acetyl- $\beta$-D-glucosaminidase isoenzymes as biomarker 
of renal dysfunction caused by cadmium in general population. Environ. Res., 81, 167.

[39] B. Shlomo, Z. Xiang, S-T, et al., (2008) Transcriptome Analyses in Normal Prostate Epithelial Cells Exposed to Low-Dose Cadmium: Oncogenic and Immunomodulations Involving the Action of Tumor Necrosis Factor. Environ. Health Perspect, 116(6), 769-776.

[40] Q. Shang and S. W. Cai, (1993) Relationship between cadmium intake and renal damage in cadmium-contaminated area population. J. Environ. Health, 10(5), 193-196.

[41] S. Cai, L. Yue, T. Jin, et al., (1998) Renal dysfunction from cadmium contamination of irrigation water: doseresponse analysis in a Chinese population. Bulletin, 76(2), 153-159.

[42] K. Nogawa, R. Honda, R. Tsuritani, et al., (1989) A dose response analysis of cadmium intake limit. Environ. Res., 48(1), 7-16.

[43] E. Kobayashi, Y. Okubo, Y. Sowazonu, et al., (2002) Association between urinary calcium excretion level and mortality in inhabitants of the Jinzu river basin area of Japan. Biolog Trace Elem Res., 89(2), 145-154.

[44] N. Hiroto and N. Hiroto, (2003) Effects of low-dose cadmium exposure on biological examinations. The Science of the Total Environment, 308, 49-62.

[45] N. Chiyoda, E. Kobayashi, Y. Okubo, et al., (2003) Allowable level of lifetime cadmium intake calculated from the individuals in the Jinzu river basin of Japan. Biolog Trace Elem Res., 96(1-3), 9-20.

[46] W. Curtis, M. Sara, C. Dave, et al., (2002) Effects of exposure to low levels of environmental cadmium on renal biomarkers. Environ. Health Perspect, 110, 151-155.

[47] D. K. T. Laura, H. Susan, N. Mark,et al., (2009) Early Kidney Damage in a Population Exposed to Cadmium and Other Heavy Metals. Environ. Health Perspect, 117(2), 181-184.

[48] H. Nakagawa, M. Nishijo, Y. Morikawa, et al., (1993) Urinary beta-2-microglobulin concentration and Mortality in a cadmium-polluted area. Arch. Environ. Health, 48, 428-435.

[49] S. Kawano, H. Nakagawa, Y. Okumura, et al., (1986) Amortality study of patients with Itai-Itai disease. Environ. Res., 40(1), 98-102.

[50] E. Kobayashi, Y. Okubo, Y. Suwazono, T. Kido, et al., (2002) Dose-response relationship between total cadmium intake calculated from the cadmium concentration in rice collected from each household of farmers and renal dysfunction in inhabitants of the Jinzu River basin, Japan. J. Appl. Toxicol, 22, 431-436.

[51] K. Etsuko, O. Yasushi, S. Yasushi, et al., (2002) Association between total cadmium intake calculated from the cadmium concentration in household rice and mortality among inhabitants of the cadmium-polluted Jinzu River basin of Japan. Toxicology Letters, 129, 85-91.

[52] I. Teruhide, K. Etsuko, O. Yasushi, et al., (2001) Association between cadmium concentration in rice and mortality in the Jinzu River basin, Japan. Toxicology, 163, 23-28.

[53] H. Nakagawa, M. Nishijo, Y. Morikawa, et al., (1993) Urinary beta-2-microglobulin concentration and Morta- lity in a cadmium-polluted area. Arch. Environ. Health, 48, 428-435; K. Matsuda, E. Kobayashi, Y. Okubo, et al. (2003)
Total cadmium intake and mortality among residents in the Jinzu river basin, Japan. Arch. Environ. Health, 58(4), (http://www.findarticles.com/p/articles/mi_m0907/is 4 5 8/ai 111732609/pg 3).

[54] M. Nishijo, Y. Morikawa, H. Nakagawa, et al., (2006) Causes of death and renal tubular dysfunction in residents exposed to cadmium in the environment. Occupat Environ. Med., 63, 545-550.

[55] M. Nishijo, H. Nakagawa, Y. Morikawa, et al., (1999) Relationship between urinary cadmium and mortality among inhibitions living in a cadmium polluted area in Japan. Toxicol Lett., 108, 321-327.

[56] M. Nishijo, H. Nakagawa, Y. Morikawa, et al., (1999) Mortality of inhibitions in cadmium area: 15 year followup. Occupational and Environmental Medicine, 52, 181184.

[57] T. S. Nawrot, E. Van Hecke, L. Thijs, et al., (2008) Cadmiumrelated mortality and long-term secular trends in the cadmium body burden of an environmentally exposed population. Environ. Health Perspect, 116(12), 1620-8.

[58] S. N. Tim, V. H. Etienne, T. R. Lutgarde, et al., (2008) Cadmium-Related Mortality and Long-Term Secular Trends in the Cadmium Body Burden of an Environmentally Exposed Population. Environ. Health Perspect, 116(121), 1620-1628.

[59] M. Andy, M. Paul, K. S. Ellen, et al., (2009) Cadmium levels in urine and mortality among U.S. Adult. Environ. Health Perspect, 117(2), 190-196.

[60] B. Ritz, J. Heinrich, M. Wjst, et al., (1998) Effect of cadmium body burden on immune response of school children, Archives of Environmental Health, (http://www.findarticles.com/p/articles/mi m0907/is n4 v53/ai 21017752/pg 6).

[61] Scientific Committee on Toxixcity, Ecotoxicity and the Environ- ment (CSTEE) (2004), Opinion on the results of the Risk Assessment of: Cadmium Metal Human Health, CAS-No.: 7440-43-9, EINECS-n: 231-152-8, Cadmium Oxide Human Health, CAS-No.: 1306-19-0, EINECS-n: 215-146-2, Brussels, C7/VR/csteeop/Cdmet-oxhh/0801 $04 \mathrm{D} /$.

[62] M. Falcon, P. Vinas, E. Osuna, et al., (2002) Environmental exposure to lead and cadmium measured in human placenta. Arch Environ. Health, 57(6), 598-602.

[63] M. Nishijo, H. Nakagawa, R. Honda, et al., (2002) Effects of maternal exposure to cadmium on pregnancy outcome and breast milk. Occupat Environ. Med., 59, 394-397.

[64] A. Fischer, R. Georgieva, V. Nikolova, J. Halkova, A. Bainova, V. Hristeva, D. Penkov, and D. Alandjiisk, (2003) Health risk for children from lead and cadmium near a non-ferrous smelter in Bulgaria. Int. J. Hyg. Environ. Health, 206, 25-38.

[65] H. Epstein, J. Dejmek, P. Subart, N. Viternovaa, and R. J. Saraam, (2000) Trace metals and pregnancy outcome in the Czech Republic. Env. Epidemiol. Toxicol, 2(1), 13-19.

[66] O. Akinloye, A. O. Arowojolu, O. B. Shittu, et al., (2006) Cadmium toxicity: a possible cause of male infertility in Nigeria Reprod Biol., 6(1), 17-30.

[67] M. Kaori, K. Etsuko, O. Yasushi, et al., (2003) Total cadmium intake and mortality among residents in the Jinzu River Basin, Japan. Arch. Environ. Health, 58(4), 218-222. 
[68] J. A. McElroy, M. M. Shafer, A. Trentham-Dietz, J. M. Hampton, and P. A. Newcomb, (2006) Cadmium exposure and breast cancer risk. J. Natl. Cancer Inst., 98, 869-873.

[69] A. Akesson, B. Julin, and A. Wolk, (2008) Long-term dietary cadmium intake and postmenopausal endometrial cancer incidence: a population-based prospective cohort study. Cancer Res., 68, 6435-6441.

[70] A. Agneta, J. Bettina, and W. Alicja, (2008) Long-term Dietary Cadmium Intake and Postmenopausal Endometrial Cancer Incidence: A Population-Based Prospective Cohort Study. Cancer Res., 68(15), 6435-41.

[71] B. Celia, D. D. Shailaja, B. S. Geoffrey, et al., (2009) Cadmium-a metallohormone? Toxicol Appl Pharmacol, 238(3), 266-271.

[72] C. Nagata, Y. Nagao, C. Shibuya, et al., (2005) Urinary cadmium and serum levels of estrogens and androgens in postmenopausal Japanese women. Cancer Epidemiol Biomarkers Prev., 14(3), 705-8.

[73] V. Verougstraete, D. Lison, and P. Hotz, (2003) Cadmium, lung and prostate cancer: A systematic review of recent epidemiological data. J. Toxicol Environ. Health Part B: Critical Reviews, 6(3), 227-256.

[74] T. P. Maria, N. A. Ana, M. C. Ciprian, et al., (2008) Cadmium Exposure and Hypertension in the 1999-2004 National Health and Nutrition Examination Survey
(NHANES). Environ. Health Perspect, 116(1), 51-56.

[75] S. Y. Wu, J. Tian, T. S. Zhou, et al., (2003) Analysis on resident's spectrum of disease and death in cadmiumpolluted area. China Public Health, 19(1), 29-30 (Chinese).

[76] S. Y. Wu, J. Tian, M. Z. Wang, et al., (2004) Effect of cadmium pollution on sub-health state and chronic diseases. China Public Health, 20(9), 1053-1054.

[77] L. J. Lei, L. Chen, T. Y. Jin, et al., (2007) Estimation of benchmark dose for pancreatic damage in cadmiumexposed smelters. Toxicol Sci., 97(1), 189-195.

[78] S. Thacker, D. Stroup, R. Parrish, et al., (1996) Surveillance in environmental public health: issues, systems, and sources. Am. J. Public Health, 86(5), 633-638.

[79] U.S.CDC, Environmental public health indicators, U.S. CDC, ECEH, EHHE, (2003),

(http: // www. cdc. gov/ nceh/divisions/ehhe.htm).

[80] B. Ritz, I. Tager, and J. Balmes, (2005) Can lessons from public health disease surveillance be applied to Environmental public health tracking? Environ. Health Perspect, 113, 243-249.

[81] Q. Shang, M. M. Zhai, L. S. Yao, et al., (2009) A following up survey on cadmium level in rice in a contaminated area, Jiangxi province. J. Hygiene Research, 38(3), 296-298 (Chinese). 